\title{
SOLAR HYDROGEN PRODUCTION BY THERMOCHEMICAL REACTION: DEVELOPMENT OF A PACKED-BED REACTOR
}

\author{
D. Darfilal ${ }^{1,2, *}$, C. Seladji ${ }^{1}$, R. Bhandari ${ }^{3}$
}

\begin{abstract}
Solar water splitting is a promising process for the storage and conversion of sunlight power into cleanburning hydrogen gas, this paper presents a CFD analysis of hydrogen production via a proposed packed bed thermochemical receiver/reactor system. The idea of this study is the use of packed bed of spherical ceramic particles coated with active redox ferrite materials. The first step is an endothermic reaction, nickel ferrite ( $\mathrm{NiFe} 2 \mathrm{O} 4)$ dissociate thermally into nickel oxide $(\mathrm{NiO})$, ferrous oxide $(\mathrm{FeO})$ and oxygen at $1473 \mathrm{~K}$, this reaction take place under $2 \mathrm{KW}$ concentrated solar energy. The second is the hydrolysis step at $1073 \mathrm{~K}$ to form hydrogen and $\mathrm{NiFe} 2 \mathrm{O} 4$, the latter is recycled to the first step for a new production cycle. The CFD code solves the momentum, energy and species transport equations. The temperature fields of the reactor solid \& the fluid phases were attained using the local thermal non-equilibrium model (LTNE). The LTNE model sources terms were computed through the user-defined functions to couple the energy equations of the fluid phase and solid phase. The complete model was used to analyse numerically the reaction through the packed bed in order to predict the thermal behavior under different conditions (inlet velocity, packing arrangement and solar concentrated flux).
\end{abstract}

Keywords: Hydrogen, Packed Bed, CFD, Balls

\section{INTRODUCTION}

Hydrogen is actually considered as the most promising green fuel vector for the future as it has prodigious capability of reducing greenhouse gas and other environmental pollutants $\left(\mathrm{C}_{\mathrm{n}} \mathrm{H}_{\mathrm{m}}, \mathrm{NO}_{\mathrm{x}}\right.$, heavy metals, radioactivity) emitted by fossil energy systems. It is considered that engines operating with hydrogen [1-3] can tremendously reduce dependence on nonrenewable fuel sources [4]. Thus, the use of hydrogen as an alternative fuel vector unlocks potential means of converting energy from solar radiation to storable chemical energy. It is envisaged that the hydrogen will replace smoothly fossil energy resources in automotive industry through fuel cell technology. It would be more efficient as fuel for internal combustion engines with comparable performance, emitting just water vapour $[4,5]$.

Historically, it is observed that there have been tendency toward the decarbonization of energy sources from solid to liquid to gaseous fuels. From coal to oil back to natural gas again, the ratio of carbon to hydrogen in the molecule of each successive source of energy has decreased [6], which confirms the global tendency towards using hydrogen as a future source of energy. Currently a growth in demand for hydrogen is observed, with major applications in Ammonia production, petroleum processing, petrochemical production, oil and fat hydrogenation, fertilizer production, metallurgical applications and electronics industry [7], it is also anticipated that interest in using hydrogen as fuel for automotive industry will further enhance the demand of the green fuel.

Hence, it is necessary to expand the existing hydrogen production capacity by using renewable energy resources, in order to meet the worlthe $d$ increasing demand. Consumption of hydrogen in different applications is shown in the following Figure [4]. There are basically three major pathways for Hydrogen production: electrochemical, thermochemical and biological methods. One of the most attractive methods for the acquisition of hydrogen could be water thermochemically splitting.

This paper was recommended for publication in revised form by Regional Editor Prof. Dr. Jaap Hoffman Hoffman 1 Département de Génie mécanique / Laboratoire Energétique et Thermique Appliquée ETAP, Abou-Bekr BELKAÏD University, B.P 119, 13000 Tlemcen, Algeria

2 Centre de Développement des Satellites CDS/ Algerian Space Agency ASAL / BP 4065, Ibn Rochd USTO 31130 Oran, Algeria 3 Institute for Technology and Resources Management in the Tropics and Subtropics (ITT) / Technische Hochschule Köln University of Applied Sciences

Betzdorfer Strasse $2 / 50679$ Cologne, Germany

E-mail address: seladji@yahoo.fr, ddarfilal@cds.asal.dz, ramchandra.bhandari@th-koeln.de

Orcid id: https://orcid.org/0000-0001-8538-2439, https://orcid.org/0000-0002-3940-1704, https://orcid.org/0000-0002-4892-0397 https://orcid.org/0000-0001-8538-2439

Manuscript Received 13 June 2018, Accepted 07 August 2018 
Journal of Thermal Engineering, Research Article, Vol. 6, No. 2, Special Issue 11, pp. 152-169, March,2020

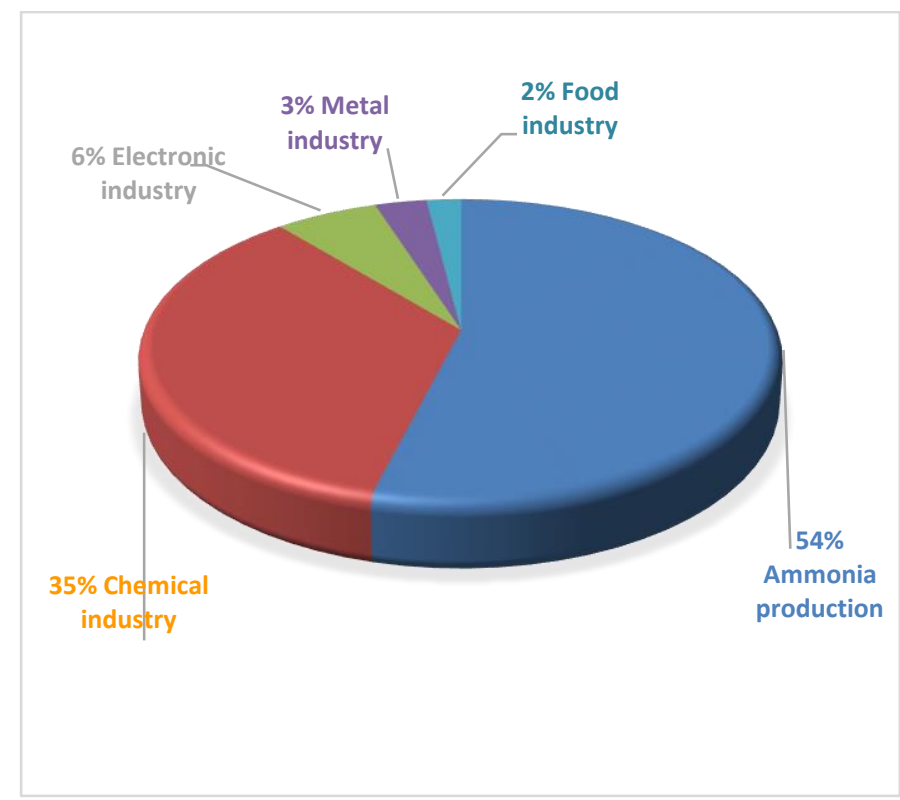

Figure 1. Hydrogen consumption by industry sector

Thermochemical hydrogen production process necessitates only water as a material input and heat as an energy source (rather than electricity for electrolysis process). The output of the process is $\mathrm{H}_{2}$ and $\mathrm{O}_{2}$. The process itself comprises a set of chemical reactions, which sum the splitting of $\mathrm{H}_{2} \mathrm{O}$ molecule [8].

$$
\begin{gathered}
\mathrm{H}_{2} \mathrm{O}+\mathrm{M} \rightarrow \mathrm{MO}+\mathrm{H}_{2} \\
\mathrm{MO} \rightarrow \mathrm{M}+\frac{1}{2} \mathrm{O}_{2} \\
\mathrm{H}_{2} \mathrm{O} \rightarrow \mathrm{H}_{2}+\frac{1}{2} \mathrm{O}_{2}
\end{gathered}
$$

In the following section, the thermochemical Hydrogen production methods coupled with solar energy source are briefly described.

The exploitation of the massive amount of solar radiation and its conversion to chemical storable energy such as hydrogen is a subject of primary technological interest [9]. There are basically three methods and their combinations for producing hydrogen using solar radiations namely photochemical, electrochemical and thermochemical $[10,11]$. The latter is based on the use of concentrated solar radiations as the driving force that produce hydrogen from transformation of its feedstock [4]. There are different thermochemical hydrogen production pathways, namely steam reforming [12-15], gas cracking $[16,17]$ and water splitting $[9,18-20]$. There have been several papers in literature that have reviewed existing thermochemical cycles for hydrogen production [21-24]. The investigations for thermochemical cycles which could be made efficient hydrogen production from water was started worldwide in the late 1960s by James E. Funk and RM Reinstrom [8, 25].

James E. Funk [21] was the first to evaluate the energy requirements for the production of hydrogen from water and the possibility of using two-step thermochemical processes. Thermocemical cycles evaluation in [22] by Sandia National Laboratories have been investigated last decades by several researchers. From over 350 multistep thermochemical cycles initially selected [22], 14 cycles are found suitable for solar application. The most thermochemical cycles promising candidates are based on Ferrite-based metal oxides, Zinc oxide, tin oxide as well as sulfates iodine. An attractive cycle for solar hydrogen production is the two-step solar thermochemical water-splitting using redox pair metal oxides, since it implicates less complex reactions, non-corrosive and nontoxic materials. 
Journal of Thermal Engineering, Research Article, Vol. 6, No. 2, Special Issue 11, pp. 152-169, March,2020

Table 1. Investigations in solar thermochemical cycles

\begin{tabular}{|c|c|c|}
\hline Thermochemical cycle & Project & Investigator entities \\
\hline \multirow[t]{4}{*}{ Ferrite-based cycles; } & $\begin{array}{l}\text { EU-FP5 project HYDROSOL, } \\
\text { EU-FP6 project HYDROSOL } 2\end{array}$ & $\begin{array}{l}\text { APTL (GR), DLR (D), Johnson Matthey (UK), } \\
\text { StobbeTech (DK), CIEMAT (E) }\end{array}$ \\
\hline & - & CNRS-PROMES (F) \\
\hline & DOE project & $\begin{array}{l}\text { Sandia, NREL, U. of Colorado, Pinnacle West } \\
\text { (USA) }\end{array}$ \\
\hline & - & Tokyo Institute / Niigata U. (Japan) \\
\hline \multirow[t]{4}{*}{ ZnO/Zn cycle; } & - & PSI/ETH (CH), U. of Minnesota (USA) \\
\hline & EU-FP5 project SOLZINC & PSI/ETH (CH), CNRS-PROMES (F), ScanArc (S) \\
\hline & - & CNRS-PROMES (F) \\
\hline & DOE project & $\begin{array}{l}\text { Sandia, NREL, U. of Colorado, Pinnacle West } \\
\text { (USA) }\end{array}$ \\
\hline \multirow{3}{*}{ Sulfur iodine (SI) cycle; } & DOE project & Sandia, NREL,U. of Colorado, Pinnacle West (USA) \\
\hline & EU-FP6 project HYTHEC & $\begin{array}{l}\text { CEA (F), DLR (D), ProSim (F), U. of Sheffield } \\
\text { (UK), DIMI (I), Empresarios Agrupados (E) }\end{array}$ \\
\hline & EU-FP7 project HYCYCLES & $\begin{array}{l}\text { DLR (D), CEA (France), ETH (CH), U. of Sheffield } \\
\text { (UK), BoosTec (F), Empresarios Agrupados (E), } \\
\text { APTL (GR), JRC (EU), ENEA (I), General Atomics } \\
\text { (USA), Westinghouse (USA), JAEA (Japan), } \\
\text { CSIRO (Australia) }\end{array}$ \\
\hline Cerium-based cycles; & - & CNRS-PROMES (F) \\
\hline UT3-cycle; & - & ENEA (I) \\
\hline $\mathrm{SnO}_{2} / \mathrm{SnO}$ cycle ; & - & CNRS-PROMES (F) \\
\hline $\begin{array}{l}\text { Hybrid sulfuric acid } \\
\text { cycle; }\end{array}$ & EU-FP6 project HYTHEC & $\begin{array}{l}\text { CEA (F), DLR (D), ProSim (F), U. of Sheffield } \\
\text { (UK), DIMI (I), Empresarios Agrupados (E) }\end{array}$ \\
\hline
\end{tabular}

Recently, enormous efforts has been made in developing concentration systems that exceed 5000 suns solar concentration ratios, capable of achieving temperatures above $1400^{\circ} \mathrm{C}$, which are needed to release two-step thermochemical reactions using metal oxide. Ferrite-based thermochemical cycle has been the most explored cycle [23], it was demonstrated at $3 ; 100 ; 750 \mathrm{~kW}$ level within the project HYDROSOL, HYDROSOL 2 , HYDROSOL-PLANT successively. The SiC-based monolith reactor model, was similar to the catalytic converter used for automobiles exhaust gas treatment catalytic converter. The reactor is constructed from ceramic multichanneled monoliths that absorbs the solar radiation flux [24]. The Ferrite-based cycle has been extensively studied in the solar furnace of Tokyo Institute of Technology [25] and Sandia National Laboratories [22, 26] with locally developed solar reactor prototypes.
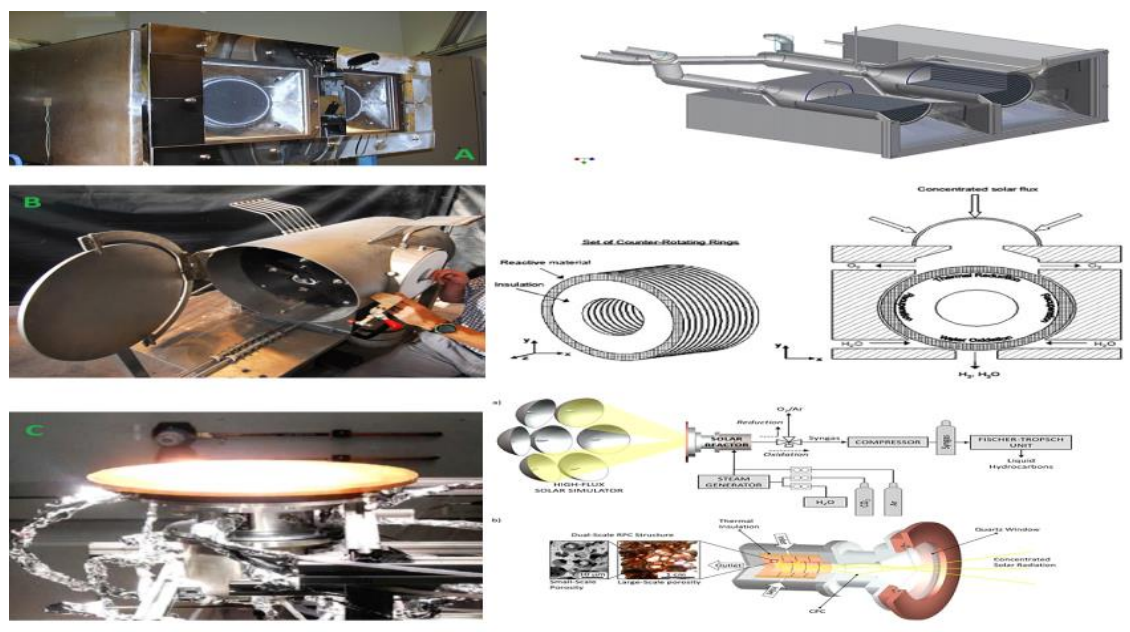

Figure 2. Solar reactors: (A) HYDROSOL 2 reactor, (B) CR5 reactor, (C) SOLARJET reactor 
Journal of Thermal Engineering, Research Article, Vol. 6, No. 2, Special Issue 11, pp. 152-169, March,2020

$\mathrm{ZnO} / \mathrm{Zn}$ cycle is one of the most researched thermochemical cycles, the $\mathrm{ZnO}$ reduction to $\mathrm{Zn}$ and $\mathrm{O}_{2}$ at high temperatures have been experimentally demonstrated mainly at PSI, CNRS-PROMES and UD FCRL USA.

$$
\begin{gathered}
\text { Reduction step } \\
\mathrm{ZnO} \rightarrow \mathrm{Zn}+\frac{1}{2} \mathrm{O}_{2} \\
\text { Production step } \\
\mathrm{Zn}+\mathrm{H}_{2} \mathrm{O} \rightarrow \mathrm{ZnO}+\mathrm{H}_{2}
\end{gathered}
$$

For this chemical process, several solar reactors were developed and tested at PSI's solar furnace, ZIRRUS and ROCA reactors were demonstrated at $10 \mathrm{~kW}$ solar radiation. Temperature reached a value $>1900 \mathrm{~K}$ for both reactors.
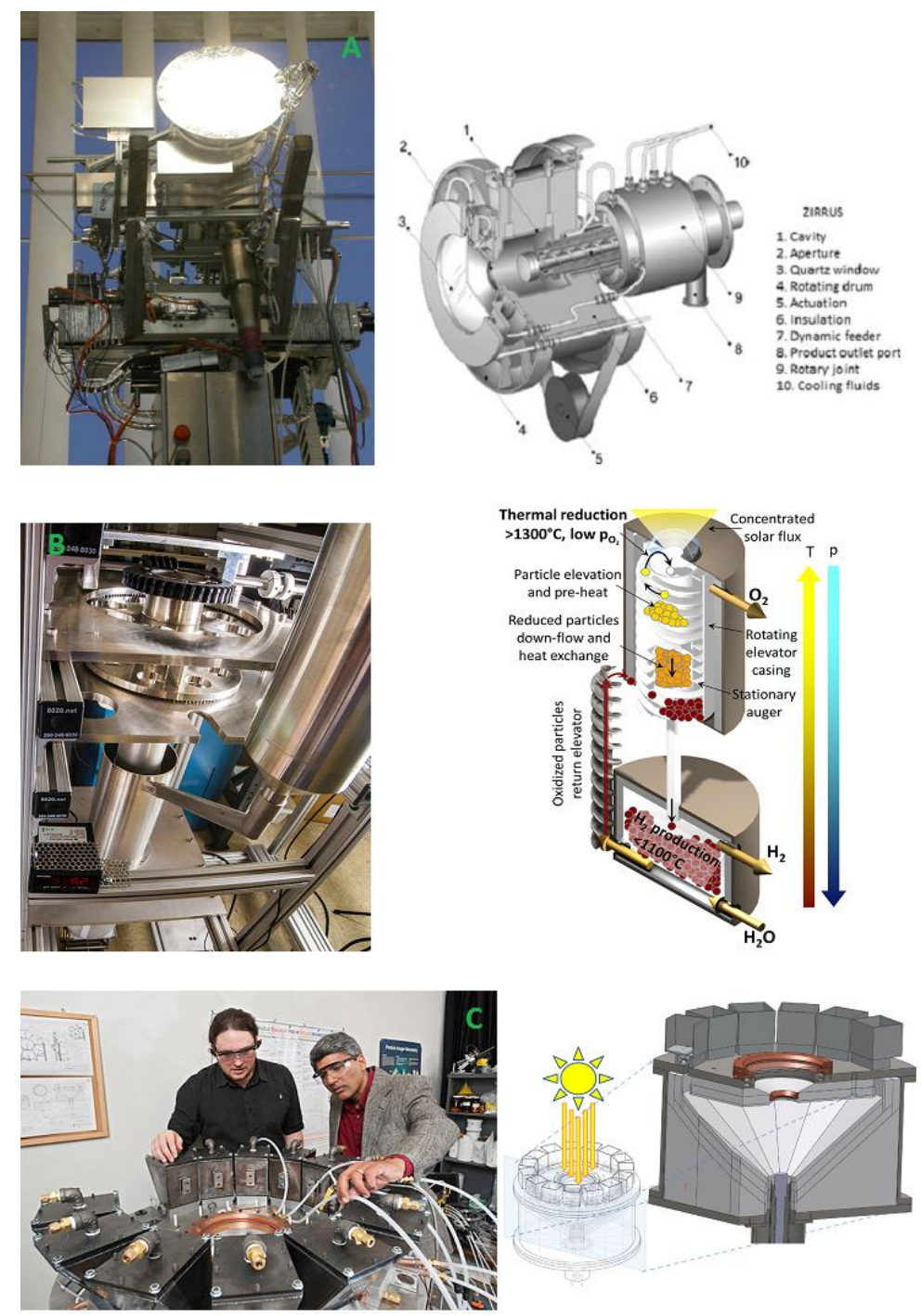

Figure 2. Solar reactors : (A) ZIRRUS reactor ; (B)2G-RC5 reactor; (C) GRAFSTRR reactor

Another promising two-step thermochemical cycle is $\mathrm{SnO}_{2} / \mathrm{SnO}$ cycle. Experiments showed that the $\mathrm{SnO}_{2}$ reduction can be performed efficiently at $1773 \mathrm{~K}$. A $1 \mathrm{~kW}$ solar reactor prototype was successfully developed and tested at CNRS-PROMES. The leading candidate for the multi-step thermochemical cycles is actually the three-step SI cycle (sulfur iodine) based on the thermal decomposition of sulfuric acid at $1123 \mathrm{~K}$. 
Journal of Thermal Engineering, Research Article, Vol. 6, No. 2, Special Issue 11, pp. 152-169, March,2020

$$
\begin{gathered}
\text { Bunsen reaction } \\
\mathrm{I}_{2}+\mathrm{SO}_{2}+2 \mathrm{H}_{2} \mathrm{O} \rightarrow 2 \mathrm{HI}+\mathrm{H}_{2} \mathrm{SO}_{4}\left(120^{\circ} \mathrm{C}\right) ; \\
\text { Distillation } \\
\mathrm{H}_{2} \mathrm{SO}_{4} \rightarrow 2 \mathrm{SO}_{2}+2 \mathrm{H}_{2} \mathrm{O}+\mathrm{O}_{2}\left(830{ }^{\circ} \mathrm{C}\right) \\
\mathrm{HI} \rightarrow \mathrm{I}_{2}+\mathrm{H}_{2}\left(450{ }^{\circ} \mathrm{C}\right)
\end{gathered}
$$

\begin{tabular}{|c|c|c|c|c|}
\hline Test facility & Reactor & $\begin{array}{l}\text { Input solar } \\
\text { power }(\mathrm{kW})\end{array}$ & Redox pairs & $\begin{array}{c}\text { Reaction } \\
\text { Temperature K }\end{array}$ \\
\hline \multirow{4}{*}{$\begin{array}{c}\text { DLR solar } \\
\text { furnace }[27-30]\end{array}$} & HYDROSOL & 3 & Ferrite-based cycles & 1523 \\
\hline & HYDROSOL-II & 100 & Ferrite-based cycles & 1473 \\
\hline & HYDROSOL-PLANT & 750 & Ferrite-based cycles & 1473 \\
\hline & Rotary Kiln & 22 & $\mathrm{CO}_{3} \mathrm{O}_{4} / \mathrm{CoO}$ cycles & 1173 \\
\hline \multirow{2}{*}{$\begin{array}{l}\text { SNL solar } \\
\text { furnace [31] }\end{array}$} & CR5 & 9 & Cerium-based cycles & 1697 \\
\hline & $2 \mathrm{G} / \mathrm{CR} 5$ & 1 & Cerium-based cycles & 1873 \\
\hline \multirow{6}{*}{$\begin{array}{c}\text { PSI solar } \\
\text { furnace } \\
\text { Switzerland [32] }\end{array}$} & GRAFSTRR & 10 & ZnO/Zncycle & 1900 \\
\hline & SYNMET & 5 & $\mathrm{ZnO} / \mathrm{Zn}$ cycle & 1600 \\
\hline & SYNPET5 & 5 & Steam gasification of petcoke & 1800 \\
\hline & TREMPER & & $\mathrm{MnO}_{2}, \mathrm{Fe}_{2} \mathrm{O}_{3}$ and $\mathrm{Fe}_{3} \mathrm{O}_{4}$ reduction & 2080 \\
\hline & ROCA & 10 & $\mathrm{ZnO} / \mathrm{Zn}$ cycle & 2000 \\
\hline & ZIRRUS & 10 & $\mathrm{ZnO} / \mathrm{Zn}$ cycle & 1900 \\
\hline EU-project & SOLREF & $300-500$ & & 1123 \\
\hline \multirow{2}{*}{$\begin{array}{c}\text { Solar furnace of } \\
\text { CNRS-PROMES } \\
\text { in Odeillo, } \\
\text { France.[33] }\end{array}$} & SOLHYCARB & $5,10,50$ & Cracking of $\mathrm{CH}_{4}$ & 2073 \\
\hline & $\begin{array}{l}\text { ROTARY CAVITY SOLAR } \\
\text { REACTOR }\end{array}$ & 1 & $\mathrm{ZnO} / \mathrm{Zn}$ cycle & 1773 \\
\hline $\begin{array}{c}\text { NREL in } \\
\text { Golden, } \\
\text { Colorado [34] }\end{array}$ & TUBULAR REACTOR & 10 & $N G$ dissociation & 2000 \\
\hline ETH Zurich [35] & SOLARJET & & Cerium-based cycles & 1773 \\
\hline $\begin{array}{c}\text { Tokyo Institute } \\
\text { of Technology } \\
\text { [25] }\end{array}$ & TTR Reactor & 20 & Ferrite-based cycles & 1773 \\
\hline $\begin{array}{c}\text { UD FCRL USA } \\
{[36]}\end{array}$ & GRAFSTRR reactor & 10 & $\mathrm{ZnO} / \mathrm{Zn}$ cycle & \\
\hline \multirow{2}{*}{$\begin{array}{c}\text { IMDEA Energy } \\
\text { solar }\end{array}$} & & 1 & $\mathrm{Mn}_{3} \mathrm{O}_{4}$ reduction & 1673 \\
\hline & & 2 & $\begin{array}{l}\mathrm{Mn}_{2} \mathrm{O}_{3}, \mathrm{Mn}_{3} \mathrm{O}_{4} \text { and } \mathrm{CeO}_{2} \\
\text { reduction }\end{array}$ & 1723 \\
\hline
\end{tabular}

The SI cycle was demonstrated within the USA DOE project, EU-FP6 HYTHEC and EU-FP7 HYCYCLES projects.

Table 2. Summary of experimental solar reactors developments. 

March,2020

In order to build a low cost feasible solar reactor, a packed bed based on ceramic is proposed. The body of this reactor/ receiver consists of spherical balls made of silicon carbide coated with the reactive ferrites material. The idea of studying the packed bed solar receiver/reactor is interesting because:

- The spheres/ beads are inexpensive compared to the monolithic or foam structured media, and can fill the space of the cavity without issues of peripheral support/packing.

- The wash-coating procedures are much easier and homogeneous than other porous structure previously used geometry.

Packed bed based on particles may be designed in many cases as a set of identical spheres occupying a determined space.

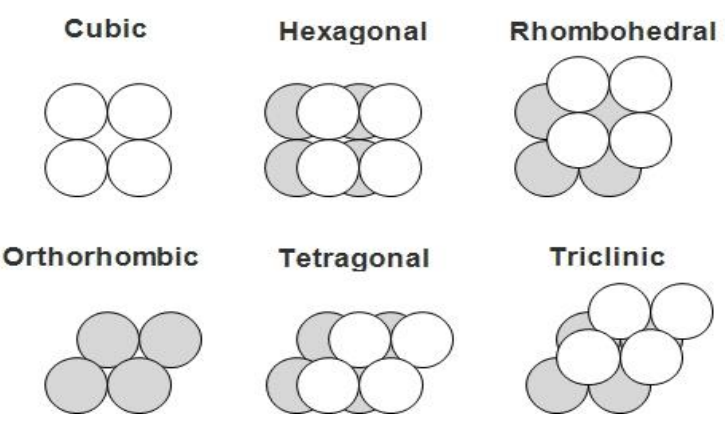

Figure 3. Reactor packing arrangement

When this space is limited to a predetermined space, such as cylindrical channels of a nanostructured porous structure filled by atoms or molecules of a substance, the geometric $\&$ thermophysical properties (Thermal conductivity, porosity ..) of the resulting porous matrix strongly depend on the arrangement (Porosity as example in [37-39].

Table 3. Effect of the arrangement on the porosity

\begin{tabular}{|l|l|}
\hline Structure & Porosity \% \\
\hline Cubic & 47.6 \\
\hline Hexagonal & 39.5 \\
\hline Rhombohedral & 26 \\
\hline Orthorhombic & 39.5 \\
\hline Tetragonal & 30.2 \\
\hline Triclinic & 26 \\
\hline
\end{tabular}

Packed beds are used in a large industrial thermal-fluid systems applications, such as nuclear reactors [40, 41], catalysts [42], and in cryogenics [43, 44]. A number of exploratory studies investigated solar thermochemical reaction in packed bed reactor [45-48]. In Figure 4 a $5 \mathrm{~kW}$ solar reactor, subjected to solar radiation up to 2953 suns and operated at temperatures up to $1490 \mathrm{~K}$ was demonstrated at PSI [49].

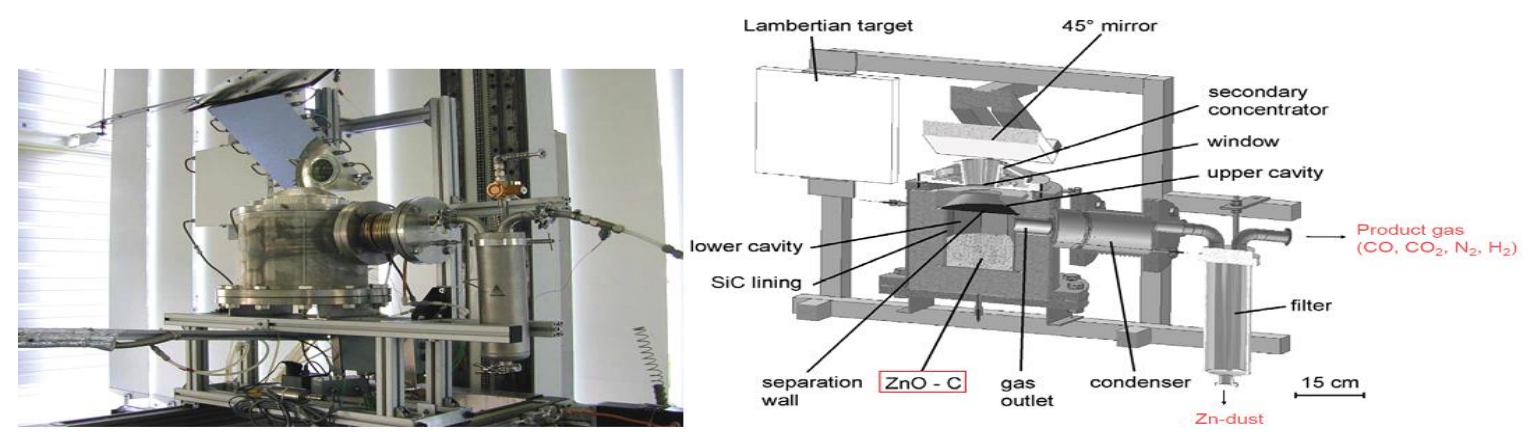

Figure 5. SOLZINC packed bed reactor [49] 

March,2020

The aim of the present paper is to study the feasibility of using this kind of porous structure as a receiver/reactor for direct thermal water splitting. It is important to mention that this specific design of directly irradiated reactor using ceramic balls, has not been studied extensively before, and could be very interesting technically.

\section{REACTOR DESCRIPTION}

The receiver/reactor body (Figure 6) consists of a cylindrical chamber ( $0.05 \mathrm{~m}$ internal diameter and 0.05 $\mathrm{m}$ long) that contains the ceramic spherical balls. The front of the receiver/reactor is directly irradiated by concentrated solar energy (maximal power of $2 \mathrm{~kW}$ constant solar flux density distribution).

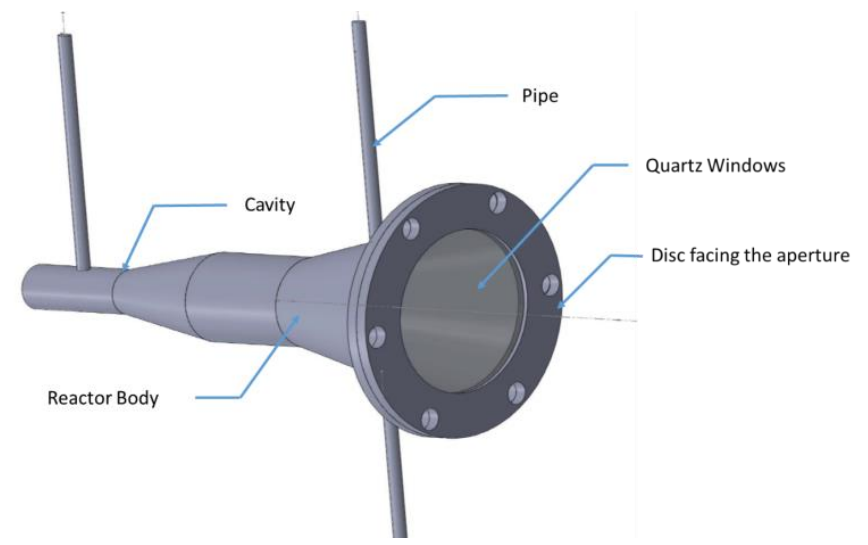

Figure 7. Reactor design

The chamber of the reactor is surrounded by an insulator. A glass window is proposed to separate the system from the ambient to provide a controlled environment inside the chamber.

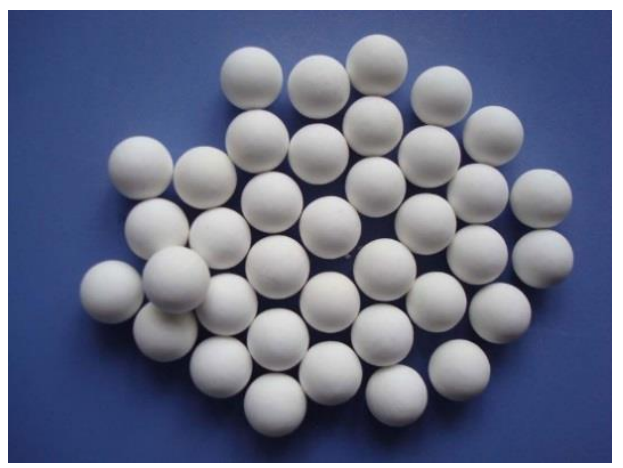

Figure 7. Ceramic balls [50]

\section{MATHEMATICAL AND NUMERICAL MODELLING}

The study presents an approach to the computational modelling of a volumetric solar receiver/reactor consisting of an absorption cavity that is filled by a packed bed of ceramic spheres and irradiated from the flow inlet face. The variation of cavity thermal response is examined for a different sphere packing arrangements while a comparison against third party experimental results is shown. The model of the bed of packed spheres is based on a two-dimensional scalar transport in a homogeneous porous medium for which distinct solid and fluid temperature fields are retained.

The model approach used in this model is macroscopic, which is based on the averaging of fundamental flow equations such as continuity, momentum and energy as well as turbulence over a representative volume of the porous media [51]. The most research efforts in computation of turbulent flow in porous media [52-54] have 
Journal of Thermal Engineering, Research Article, Vol. 6, No. 2, Special Issue 11, pp. 152-169, March,2020

been focused on developing macroscopic equations through the averaging volume techniques of the $\mathrm{k}-\varepsilon$ turbulence model.

The governing equation assumptions are the following:

- Uniform porosity through the porous structure.

- The flow field is steady and turbulent

- Effect of Buoyancy, Hydrodynamic dispersion, viscous dissipation are negligible.

- Thermal expansion is negligible.

\section{Continuity and momentum equation}

According to the cited assumptions, the averaged continuity and momentum equation for the proposed model are:

$$
\begin{gathered}
\nabla(\rho \vec{v})=0 \\
-\frac{\mu}{\alpha}<v>-\frac{\rho_{f} C_{2} \varepsilon_{p}}{\sqrt{\alpha}}[<v>.<v>]+\frac{\mu}{\varepsilon_{p}} \nabla^{2}<v>-\nabla<P>=0
\end{gathered}
$$

Where $\alpha$ is the permeability of the porous media, C_ 2 is the inertial coefficient. The first and the second term on the right hand side are the momentum source terms. The equation neglects the convective term as the flow is fully developed. The turbulence model are obtained by averaging the standard turbulence kinetic energy and the dissipation rate equation.

$$
\begin{gathered}
\nabla .\left(\rho_{f} v<k_{t}>\right)=\nabla \cdot\left[\left(\mu+\frac{\mu_{t \varepsilon}}{\sigma_{k}}\right) \nabla\left(\varepsilon_{p}<k_{t}>\right)\right] \\
+P_{i}+G_{i}-\rho_{f} \varepsilon_{p}<\varepsilon> \\
\nabla \cdot\left(\rho_{f} v<\varepsilon>\right)=\nabla \cdot\left[\left(\mu+\frac{\mu_{t \varepsilon}}{\sigma_{\varepsilon}}\right) \nabla\left(\varepsilon_{p}<\varepsilon>\right)\right]+ \\
C_{1} P_{i} \frac{<\varepsilon>}{<k_{t}>}+C_{2} \frac{<\varepsilon>}{<k_{t}>}\left(G_{i}-\rho_{f} \varepsilon_{p}<\varepsilon>\right)
\end{gathered}
$$

\section{Energy equations}

In LTNE energy model approach, the solid and fluid phases are spatially coincident and interact between them with regard to heat transfer (source term), two equation are solved separately for the fluid and solid phases in this proposed model. The Fluid phase equation under steady state conditions is:

$$
\left(\rho C_{p}\right)_{f}<v>. \nabla<T_{f}>=\nabla .\left\{k_{f e f f} . \nabla<T_{f}>\right\}+S_{c o n v}
$$

Solid phase energy equation under steady state condition is the following:

$$
\nabla \cdot\left\{k_{\text {seff }} . \nabla<T_{s}>\right\}-S_{\text {conv }}=0
$$

S_(conv ) Present the source term of the convective heat exchange between the solid and the fluid phases. 
Journal of Thermal Engineering, Research Article, Vol. 6, No. 2, Special Issue 11, pp. 152-169, March,2020

$$
S_{\text {conv }}=h_{f s} A_{f s}\left(<T_{s}>-<T_{f}>\right)
$$

Where $h_{f s}$ present the coefficient of the convective volumetric heat transfer and $A_{f s}$ is the exchange area $b$ the solid matrix and the fluid.

\section{Convective volumetric heat transfer coefficient}

According to the following references [55] and [56] the volumetric heat transfer coefficient is constant over the length of the reactor. Table 4 gives an overview of some models existing in the literatue.

Table 4. Different models for the volumetric heat transfer coefficient

\begin{tabular}{|c|c|c|}
\hline $\mathbf{h}_{\mathrm{fs}}=\overline{\mathbf{h}_{\mathrm{fs}}}$ & $\mathbf{A}_{\mathrm{fs}}$ & Ref \\
\hline $\begin{array}{c}{\left[2,096 \varepsilon_{p}^{0,38} \lambda_{f} \cdot R e^{0,438} \cdot\left(-8.278 \varepsilon_{p}^{0,38}+\right.\right.} \\
57,384 \varepsilon_{p}^{1,38}-106,63 \varepsilon_{p}^{2,38}+ \\
\left.\left.95,756 \varepsilon_{p}^{3,38}-37,24 \varepsilon_{p}^{4,38}\right)\right] / d_{s}^{2} \\
\text { For }\left(0.66<\varepsilon_{p}<0.93\right) \&(0.66<\operatorname{Re}<0.93)\end{array}$ & & [57] \\
\hline$\frac{k_{f}\left(2+1,1 \cdot P r^{\frac{1}{3}} \cdot R e^{0.6}\right)}{d_{p}}$ & $\frac{6 .\left(1-\varepsilon_{p}\right)}{d_{p}}$ & [58] \\
\hline $\begin{array}{l}0,0040\left(\frac{k_{f}}{d_{v}}\right) \cdot \operatorname{Pr}^{\frac{1}{3}} \cdot \operatorname{Re}^{1.35} \quad(\operatorname{Re}<100) \\
0,0156\left(\frac{k_{f}}{d_{v}}\right) \cdot \operatorname{Pr}^{\frac{1}{3}} \cdot \operatorname{Re}^{1.04} \quad(\operatorname{Re} \geq 100)\end{array}$ & $\begin{array}{l}20,346 \cdot(1 \\
\left.-\varepsilon_{p}\right) \varepsilon_{p}^{2}\end{array}$ & [59] \\
\hline$\left(\frac{d_{p} \cdot \varepsilon_{p}}{0,5555 \cdot \operatorname{Pr}^{\frac{1}{3}} \operatorname{Re}^{2 / 3} \cdot k_{f}}+\frac{d_{p}}{10 \cdot k_{s}}\right)^{-1}$ & $\frac{6 .\left(1-\varepsilon_{p}\right)}{d_{p}}$ & {$[60]$} \\
\hline $\begin{array}{l}\quad\left(\left(1.18 \operatorname{Re}^{0.58}\right)^{4}+\left(0.23 \operatorname{Re}_{\mathrm{h}}^{0.75}\right)^{4}\right)^{\frac{1}{4}} /\left(d_{p} k_{f}\right) \\
\text { Where } \operatorname{Re}_{\mathrm{h}}=\frac{R e}{1-\varepsilon_{p}}\end{array}$ & $\frac{6 .\left(1-\varepsilon_{p}\right)}{d_{p}}$ & [61] \\
\hline
\end{tabular}

The model used to find the heat transfer correlation and the interfacial area density is a general correlation, which can be used for all Particle Reynolds Number [62]

$$
h_{f s}=\frac{k_{f}\left(2+1,1 \cdot \operatorname{Pr}^{\frac{1}{3}} \cdot R e^{0.6}\right)}{d_{p}}
$$

The area correlation for this model is given by: 
Journal of Thermal Engineering, Research Article, Vol. 6, No. 2, Special Issue 11, pp. 152-169, March,2020

$$
A_{f s}=\frac{6 \cdot\left(1-\varepsilon_{p}\right)}{d_{p}}
$$

\section{Effective conductivity}

The Effective thermal conductivity is the thermal conductivity used in porous media, it is calculated generally through correlations. The most accurate formula [63] is used in this study. (The default model used in ANSYS FLUENT)

$$
\begin{aligned}
& k_{f}=\left(\begin{array}{ll}
\varepsilon & k_{f}
\end{array}\right) \\
& k_{s}=\frac{1}{3}(1-\varepsilon) \times k_{s} \\
& k_{e f f}=\left(\varepsilon k_{f}\right)+\frac{1}{3}(1-\varepsilon) \times k_{s}
\end{aligned}
$$

\section{Permeability and inertial loss coefficients}

Ergun Equation is a semi empirical correlation applicable over a vast range of Reynold numbers and it is applicable for many type of packing:

$$
\frac{|\Delta p|}{L}=150 \frac{\mu}{D_{p}^{2}}\left((1-\varepsilon)^{2} / \varepsilon^{3}\right) v_{\infty}+\left(1.75 \rho / D_{p}\right)\left((1-\varepsilon) / \varepsilon^{3}\right) v_{\infty}^{2}
$$

From Ergun correlation, the permeability and inertial loss coefficients are identified as:

$$
\begin{gathered}
\propto=\frac{D_{p}^{2}}{150} \frac{\varepsilon^{3}}{(1-\varepsilon)^{2}} \\
C_{2}=\frac{3.5}{D_{P}} \frac{(1-\varepsilon)}{\varepsilon^{3}}
\end{gathered}
$$

\section{Species transport equation}

In this work, the two steps reactions were modeled separately (reduction and hydrolysis). The main objectives of these simulations are to study the kinetics of the reactions and the evaluation of the impact of these reactions on the temperature distribution.

The species transport equation is expressed as:

$$
\nabla\left(\rho \vec{u} Y_{i}\right)=\rho D_{i, m} \Delta Y_{i}+M_{i} R_{\text {chem }, i}
$$



March,2020

\section{Reduction reaction:}

The thermal reduction is an endothermic reaction, it needs a temperatures $>1400 \mathrm{~K}$ [6]. In this case the source term related to the chemical reaction (using Arrhenius-type temperature dependence model) is given by:

$$
S_{R}=k_{0, R} \exp \left(\frac{-E_{a, R}}{R_{g} T_{s}}\right) \Delta H_{r e d}
$$

\section{Hydrolysis reaction:}

The second step of the cycle is an exothermic reaction. This reaction is carried out at temperatures around $1200 \mathrm{~K}$. The volumetric heat source term in this case is given by:

$$
S_{H}=k_{0, H} \exp \left(\frac{-E_{a, H}}{R_{g} T_{s}}\right)\left[H_{2} O\right] \Delta H_{h y d}
$$

\section{Boundary condition}

The walls were considered as static and adiabatic with an initial static temperature of $300 \mathrm{~K}$, the inlet pressure of the fluid was defined to have a pressure of (1000 Pa above the atmospheric pressure). For the outlet boundary, the pressure was set to a value of $0 \mathrm{~Pa}$.

\section{Methodology of resolution}

The physical model is a packed bed symmetric cylindrical, a two-dimensional mesh was generated and used in this study. This two dimensional heat transfer problem was solved using the CFD Computational Fluid Dynamics software ANSYS FLUENT . To couple the pressure and the velocities parameters with the second order upwind method, the SIMPLE algorithm was applied. The second order upwind method was used for the advection terms in the momentum equations and for the energy equation. The LTNE model sources terms were computed through the UDF to couple the energy equations of the fluid phase and solid phases. The convergence criterion was $10^{-5}$ for all the equations of the model. Analysis were first conducted for $\mathrm{N}_{2}$ flow in order to determine the thermal behaviour of the packed bed; then chemical reactions were included into the model to analyse the reactions kinetics and their impact on the reactor thermal behaviour.

The data of the chemical reaction used in this simulation are listed below:

Table 5. Reactions data

\begin{tabular}{|c|l|}
\hline$\Delta H_{r e d}\left(\mathrm{~J} \mathrm{~mol}^{-1}\right)$ & 319000 \\
\hline$\Delta H_{h y d}\left(\mathrm{~mol}^{-1}\right)$ & 286000 \\
\hline$E_{a, R}\left(\mathrm{~J} \mathrm{~mol}^{-1}\right)$ & 240000 \\
\hline$E_{a, H}\left(\mathrm{~J} \mathrm{~mol}^{-1}\right)$ & $10^{5}$ \\
\hline$k_{0, R}\left(\mathrm{~mol} \mathrm{~m}^{-3} \mathrm{~s}^{-1}\right)$ & \multicolumn{1}{|c|}{$10^{6}$} \\
\hline$k_{0, H}\left(\mathrm{~s}^{-1}\right)$ & 35 \\
\hline$\psi\left(\mathrm{mol} \mathrm{m}^{-2}\right)$ & 0.1 \\
\hline
\end{tabular}


Journal of Thermal Engineering, Research Article, Vol. 6, No. 2, Special Issue 11, pp. 152-169, March,2020

Table 6. Properties of the materials [64-67]

\begin{tabular}{|c|c|c|c|}
\hline Properties & $\mathrm{NiFe}_{2} \mathrm{O}_{4}$ & $\mathrm{NiO}$ & $\mathrm{FeO}$ \\
\hline Density $\left(\frac{K g}{m^{3}}\right)$ & 5360 & 6670 & 5740 \\
\hline$C_{p}\left(\frac{j}{K g K}\right)$ & 564,72894 & 620 & 668,708241 \\
\hline$\lambda\left(\frac{w}{m K}\right)$ & 10 & 25,776769 & 11 \\
\hline M (g/mol $)$ & 234,38 & 74,69 & 71,84 \\
\hline S S entropy $\left(\frac{j}{K}\right.$ mol & 131370 & 37990 & 58500 \\
\hline S S enthalpy $\left(\frac{J}{K m o l}\right)$ & -1077700000 & -239700000 & -271900000 \\
\hline
\end{tabular}

\section{RESULTS \& DISCUSSIONS}

To verify the model developed, the model was validated with experimental and numerical results obtained by [68] using the same thermophysical properties of the cited model. Figure 8 presents the variation of temperature through the position. The results are showed good agreement with [68] experimental and numerical studies. In order to optimise the performances of the packed bed solar receiver, we conducted a series of sensitivity study of the inlet velocity, the balls arrangement and the inlet solar flux.
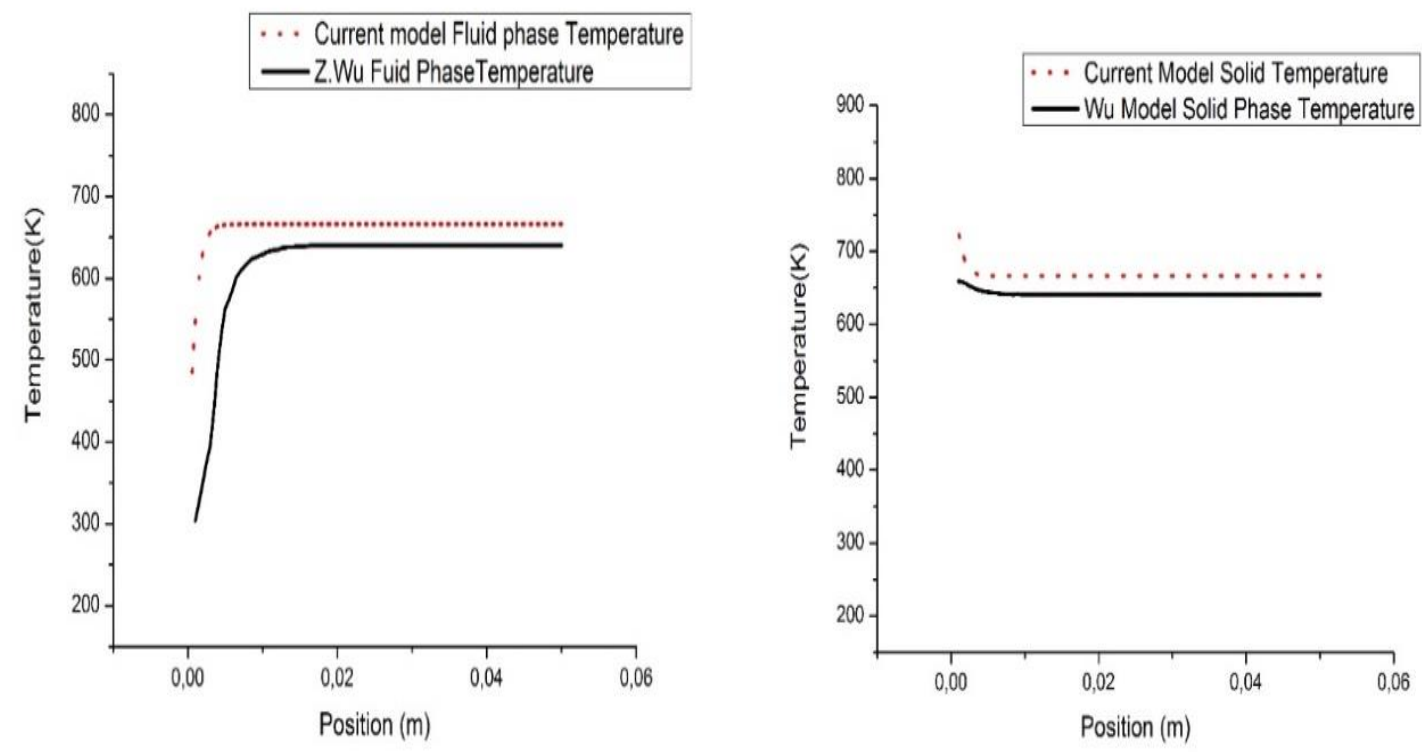

Figure 8. model validation Left hand side: fluid phase Right hand side: Solid phase 
Journal of Thermal Engineering, Research Article, Vol. 6, No. 2, Special Issue 11, pp. 152-169, March,2020
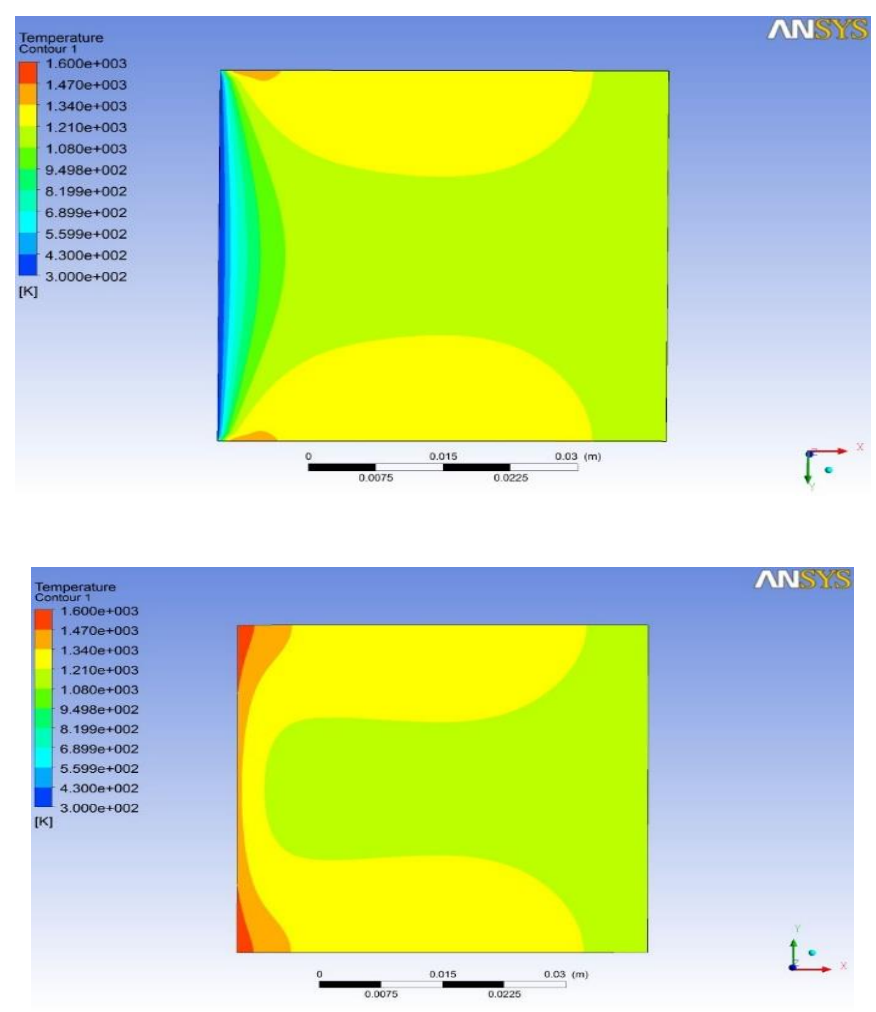

Figure 9. Temperature distribution, Left hand side: fluid phase Right hand side: Solid phase

The impact of the incident solar flux on the temperature distributions of solid and fluid phases is studied in order to select the optimum solar power flux (Figure 10. Temperature distributions along the symmetry axis under several heat flux power, Left hand side Fluid phase Right hand side: Solid phase). As a result, the optimal solar power value for the reaction at the working temperature of $1200 \mathrm{~K}$ is at least $2 \mathrm{KW}$ and it must not exceed $2.5 \mathrm{KW}$.
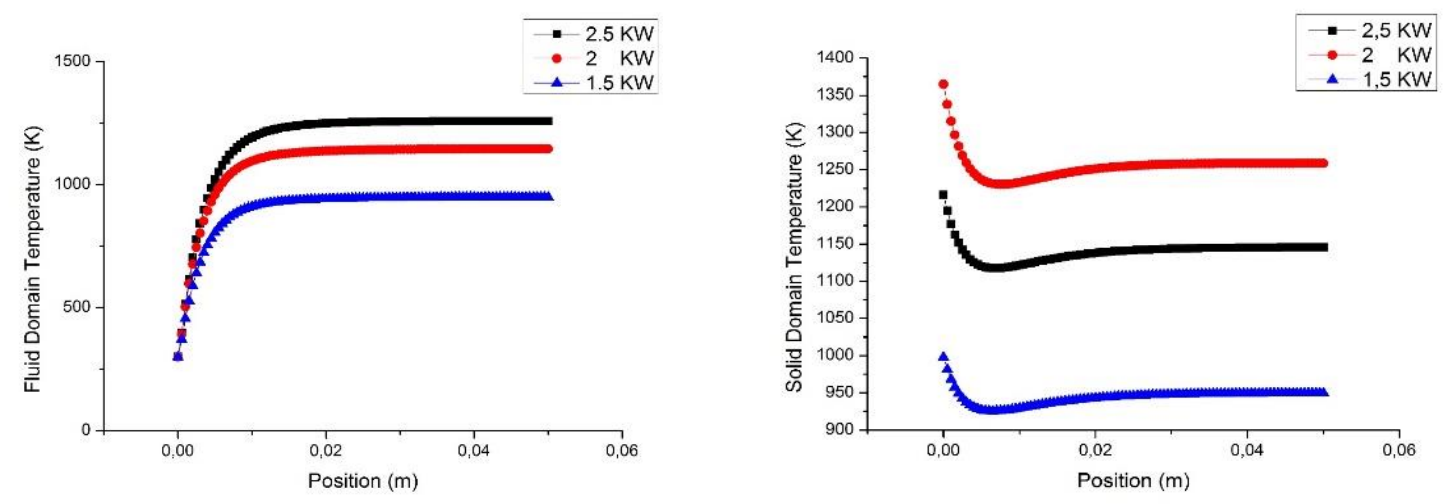

Figure 10. Temperature distributions along the symmetry axis under several heat flux power, Left hand side Fluid phase Right hand side: Solid phase

The Figure 8. Temperature distributions along the symmetry axis under several inert gas velocity, Left hand side Fluid phase Right hand side: Solid phase presents the temperature behaviours of the fluid and solid phase with same absorber properties $(\mathrm{d}=0.72 \mathrm{~mm}$, / Porosity $=0.476)$, under different inlet superficial velocity. This figure shows that when the inlet velocity increase, the outlet temperature decreases and the whole solid temperature becomes more uniform. In addition, the maximum temperature place locates always inside the absorber. 
Journal of Thermal Engineering, Research Article, Vol. 6, No. 2, Special Issue 11, pp. 152-169, March,2020
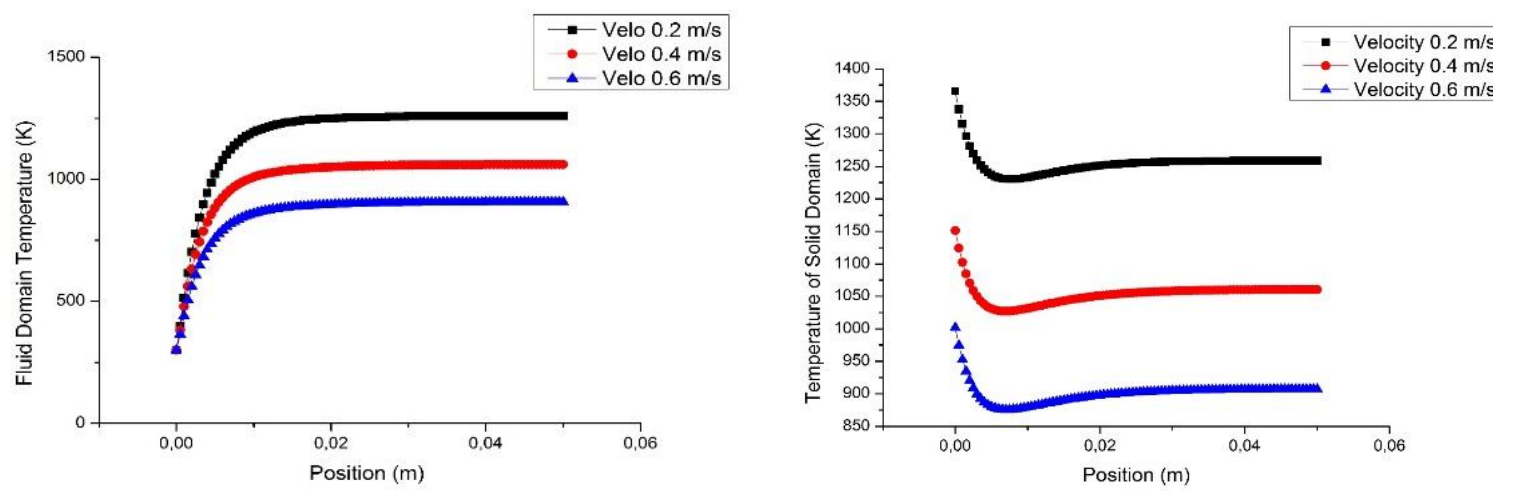

Figure 8. Temperature distributions along the symmetry axis under several inert gas velocity, Left hand side Fluid phase Right hand side: Solid phase

Another parametric study was related to the arrangement of the ceramic balls in the packed bed that affects the temperature distribution in the solid especially near the front surface of the receiver. The Figure 9. Temperature distribution, Left hand side: Solid phase (Triclinic balls arrangement) shows that the arrangement of the particles affect strongly the temperature behaviour of the receiver / reactor (comparison between Triclinic and cubic arrangements)

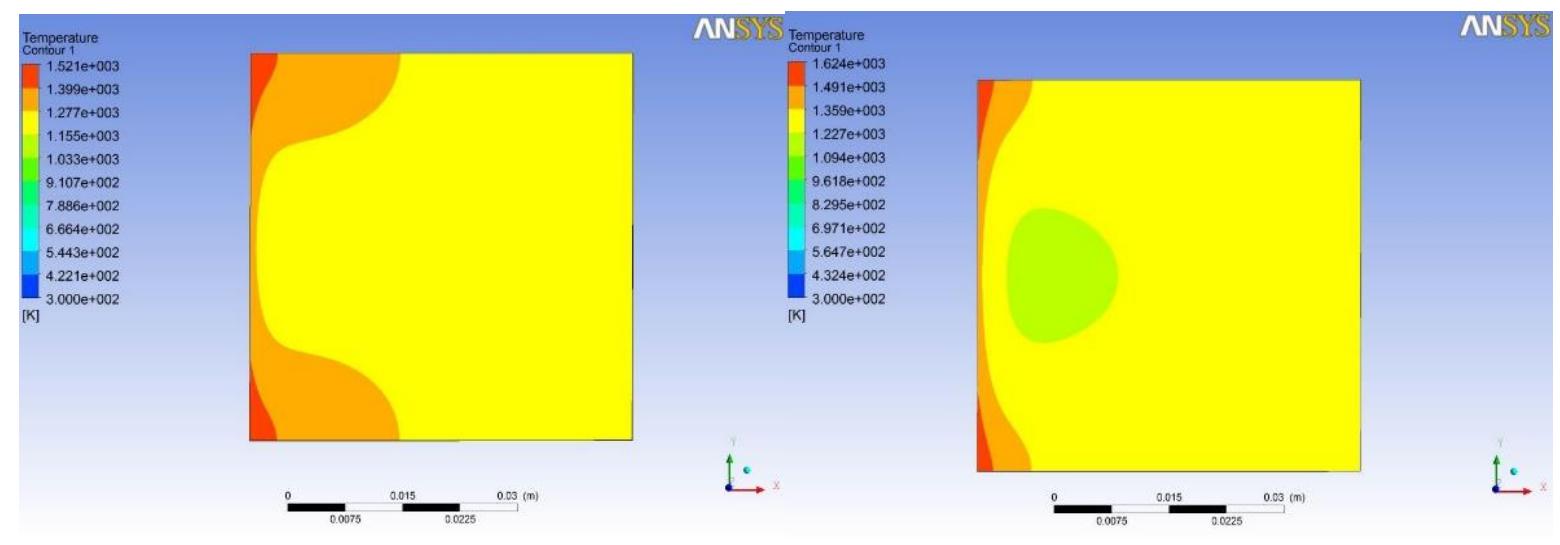

Figure 9. Temperature distribution, Left hand side: Solid phase (Triclinic balls arrangement) Right hand side: Solid phase (Cubic balls arrangement)
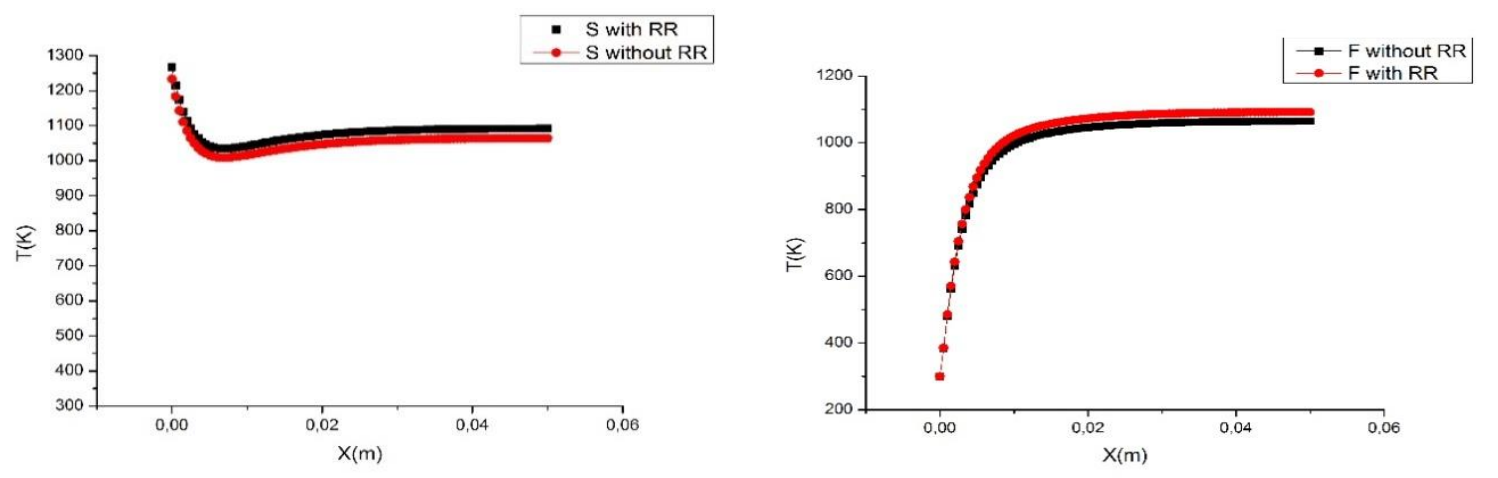

Figure 10. Fluid (F) and solid (S) temperature behaviour with and without reduction reaction 

March,2020

As expected solid and fluid temperatures decrease when accounting for the reduction reaction. Figure 13 shows the temperature distributions with and without the reduction reaction. The temperature of the solid and fluid phases tend to homogenise after about $1 \mathrm{~cm}$ from the inlet of the packed bed. Results shows that the effect of the reaction on the temperatures is limited, however, the chemical reaction only consumes a low fraction of the solar energy entering the reactor

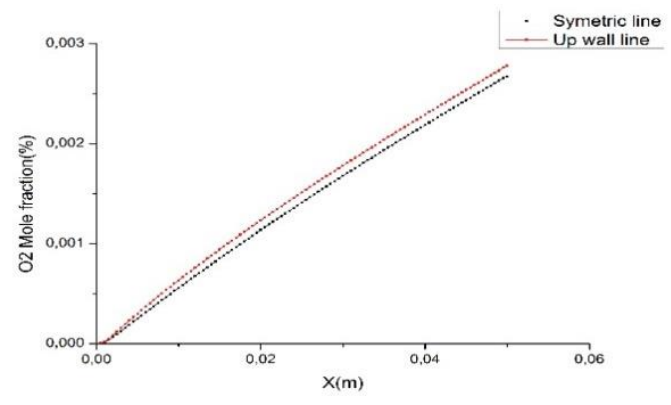

Figure 11. 02 mole fraction

Figure 14 shows the distribution of the oxygen in the reactor during the reduction step for the symmetric and wall lines. The results shows high oxygen concentrations close to the wall caused by the viscosity effect.

\section{Conclusion}

In the present study, CFD analysis of a water splitting solar reactor is given. The local thermal nonequilibrium model was used to investigate the temperature distributions. Numerical study was conducted to study the effect of the inlet velocity, solar radiation, ball arrangement and the reaction. The simulations were also compared with experimental data. The results shows that the temperature distribution depend strongly with the working conditions and the porous media properties. The results shows that the ideal temperature distribution with the maximum solid porous structure temperature located inside the absorber. It is remarkable that the packed balls arrangement has an interesting effect on the temperature distributions inside the reactor. Regarding reactive flow simulations, the impact of the reaction on the temperature distributions was analyzed, a temperature decrease reaching about $60 \mathrm{~K}$ was evidenced due to the endothermic reaction. In this study, pulsatile flow in an intracranial aneurysm is numerically investigated under the combined effect of the aneurysm size, the curvature of the artery and the flow rates. The aim of this study is to evaluate the flow field and the wall shear stress distribution along the saccular cavity wall during a cardiac cycle and use these findings to have a better understanding of the mechanism leading to the rupture of the vessel.

\section{NOMECLATURE}

$\mathrm{A}_{\mathrm{fs}} \quad$ Exchange area between the solid matrix and the fluid

$\mathbf{C}_{1}, \mathbf{C}_{2} \quad \mathrm{k}-\varepsilon$ model Inertial coefficient $[\mathrm{m}]$

Conv Convection

$C_{p} \quad$ Thermal capacity $\left[\mathrm{Jg}^{-1} \mathrm{~K}^{-1}\right]$

$D_{i, m} \quad$ Mass diffusion coefficient for the species i

$d_{p} \quad$ Mean Particle diameter [m]

eff Effective

$f \quad$ Fluid

$G_{i} \quad$ Generation rate of the intrinsic average of $k_{t}$

GHG Greenhouse gazes

$h_{f s} \quad$ Convective volumetric heat transfer coefficient $\left[\mathrm{Wm}^{-3} \mathrm{~K}^{-1}\right]$

$k_{t} \quad$ Turbulance kinetic energy $\left[\mathrm{m}^{2} \mathrm{~s}^{-2}\right]$

$k \quad$ Thermal Conductivity $\left[\mathrm{Wm}^{-1} \mathrm{~K}^{-1}\right]$

$M_{i} \quad$ Molecular weight

$P \quad$ Pressure $[\mathrm{Pa}]$

$\mathrm{Pr} \quad$ Prandtl Number 
$R_{\text {chem }, i}$ chemical source terme relates to the net rate of production of the species $\mathrm{i}$

Re Reynolds number

$\mathrm{S} \quad$ Volumetric heat source term $\left[\mathrm{W} \mathrm{m}^{-3}\right]$

$s \quad$ Solid

T Temperature

$v \quad$ Superficial Velocity $\left[\mathrm{m} \mathrm{s}^{-1}\right]$

$v^{\prime} \quad$ Velocity fluctution $\left[\mathrm{m} \mathrm{s}^{-1}\right]$

$Y_{i} \quad$ local mass fraction of species $\mathrm{i}$

$\alpha \quad$ Permeability

$\mu \quad$ Dynamic viscosity $\left[\mathrm{kg} \mathrm{m}^{-1} \mathrm{~s}^{-1}\right]$

$\rho \quad$ Density $\left[\mathrm{kg} \mathrm{m}^{-3}\right]$

$\varepsilon \quad$ Dissipation rate $\left[\mathrm{m}^{2} \mathrm{~s}^{-3}\right]$

$\varepsilon_{p} \quad$ Porosity

$\sigma_{k}, \sigma_{\varepsilon} \quad \mathrm{k}-\varepsilon$ model constants

\section{REFERENCES}

[1] White, C., R. Steeper, and A. Lutz. The hydrogen-fueled internal combustion engine: a technical review. International journal of hydrogen energy, 2006; 31(10), 1292-1305.

[2] Antunes, J.M.G. The use of hydrogen as a fuel for compression ignition engines.;2011.

[3] Antunes, J.G., R. Mikalsen, and A. Roskilly. An investigation of hydrogen-fuelled HCCI engine performance and operation. International journal of hydrogen energy, 2008; 33(20), 5823-5828.

[4] Chaubey, R., et al. A review on development of industrial processes and emerging techniques for production of hydrogen from renewable and sustainable sources. Renewable and Sustainable Energy Reviews, 2013; 23, 443462.

[5] Blok, K., et al. Hydrogen production from natural gas, sequestration of recovered $\mathrm{CO} 2$ in depleted gas wells and enhanced natural gas recovery. Energy, 1997; 22(2-3), 161-168.

[6] Dunn, S. .Hydrogen futures: toward a sustainable energy system. International journal of hydrogen energy, 2002; 27(3), 235-264.

[7] Ramachandran, R. and R.K. Menon..An overview of industrial uses of hydrogen. International journal of hydrogen energy, 1998; 23(7), 593-598.

[8] Funk, J.E..Thermochemical hydrogen production: past and present. International journal of hydrogen energy, 2001; 26(3), 185-190.

[9] Agrafiotis, C., et al. Solar water splitting for hydrogen production with monolithic reactors. Solar Energy, 79(4), 2005; 409-421.

[10] Xiao, L., S.-Y. Wu, and Y.-R. Li..Advances in solar hydrogen production via two-step water-splitting thermochemical cycles based on metal redox reactions. Renewable Energy, 2012; 41, 1-12.

[11] BIČÁKOVÁ, O. and P. Straka.The resources and methods of hydrogen production. Acta Geodyn. Geomater,2010; 7(158), 175.

[12] Epstein, M. Solar thermal reforming of methane. SFERA Winter School. Switzerland. Zürich, 2011.

[13] Giaconia, A., et al. Multi-fuelled solar steam reforming for pure hydrogen production using solar salts as heat transfer fluid. Energy Procedia,2015; 69, 1750-1758.

[14] Simakov, D.S., et al. Solar thermal catalytic reforming of natural gas: a review on chemistry, catalysis and system design. Catalysis Science \& Technology,2015; 5(4), 1991-2016.

[15] Dahl, J.K., et al. Solar-thermal processing of methane to produce hydrogen and syngas. Energy \& fuels, 2001; $15(5), 1227-1232$.

[16] Abanades, S. and G. Flamant. High-temperature solar chemical reactors for hydrogen production from natural gas cracking. Chemical Engineering Communications, 2008; 195(9), 1159-1175.

[17] Abánades, A., et al. Experimental analysis of direct thermal methane cracking. International journal of hydrogen energy, 2011; 36(20), 12877-12886.

[18] Steinfeld, A. Solar hydrogen production via a two-step water-splitting thermochemical cycle based on $\mathrm{Zn} / \mathrm{ZnO}$ redox reactions. International journal of hydrogen energy,2002; 27(6), 611-619.

[19] Abanades, S. and G. Flamant. Thermochemical hydrogen production from a two-step solar-driven watersplitting cycle based on cerium oxides. Solar Energy,2006; 80(12), 1611-1623. 
Journal of Thermal Engineering, Research Article, Vol. 6, No. 2, Special Issue 11, pp. 152-169, March,2020

[20] Tamaura, Y., et al. Production of solar hydrogen by a novel, 2-step, water-splitting thermochemical cycle. Energy, 1995; 20(4), 325-330.

[21] Funk, J.E. and R.M. Reinstrom. Energy requirements in production of hydrogen from water. Industrial \& Engineering Chemistry Process Design and Development, 1966; 5(3), 336-342.

[22] Perret, R. Solar Thermochemical hydrogen production research (STCH), Sandia National Lab.(SNL-CA), Livermore, CA (United States), 2011.

[23] Yadav, D. and R. Banerjee A review of solar thermochemical processes. Renewable and Sustainable Energy Reviews, 2016; 54, 497-532.

[24] Konstandopoulos, A.G. and S. Lorentzou. Novel Monolithic Reactors for Solar Thermochemical Water Splitting. On Solar Hydrogen \& Nanotechnology,2009; 621-639.

[25] Kaneko, H., et al..Simulation study of Tokyo Tech rotary-type solar reactor on solar field test at CSIRO in Australia. in Proceedings of the ASME 2011 5th International Conference on Energy Sustainability (ES2011), ESFuelCell2011-54568,2011; Washington, DC.

[26] ADMIN. High-Efficiency Solar Thermochemical Reactor for Hydrogen Production. 2014 [cited 201722 august]; Available from: http://energy.sandia.gov/high-efficiency-solar-thermochemical-reactor-for-hydrogenproduction/.

[27] Neises, M., et al. Solar-heated rotary kiln for thermochemical energy storage. Solar Energy, 2012; 86(10), 3040-3048.

[28] Roeb, M., et al. Technologies and trends in solar power and fuels. Energy \& Environmental Science,2011; 4(7), 2503-2511.

[29] Pagliaro, M., et al. Solar hydrogen: fuel of the near future. Energy \& Environmental Science, 2010; 3(3), 279287.

[30] EnergyBusinessEurope. HYDROSOL Plant Project - Hydrogen power for zero CO2 emissions. 2016 [cited 2017 21/08]; Available from: http://www.energybusinesseurope.com/hydrogen-power-for-zero-co2-emissionsand-energy-security/.

[31] OTERO, A. Concentrating on Sunshine to Advance the Hydrogen Economy. 2013 [cited 201722 August]; Available from: http://crf.sandia.gov/concentrating-on-sunshine-to-advance-the-hydrogen-economy/.

[32] Alonso, E. and M. Romero..Review of experimental investigation on directly irradiated particles solar reactors. Renewable and Sustainable Energy Reviews,2015; 41, 53-67.

[33] CHAMBON, M. Thermochemical cycles based on the $\mathrm{ZnO} / \mathrm{Zn}$ or $\mathrm{SnO} 2 / \mathrm{SnO}$ redox couples : Kinetic characterizations and study of solar reactors, SFERA Winter School Solar Fuels \& Materials: ETH Zürich, 13; 2011.

[34] Lichty, P.R., et al. Solar thermal reactor materials characterization, National Renewable Energy Laboratory (NREL), Golden, CO.2008.

[35] TRANSPORT, E.F.-A.a.A. The SOLAR-JET Project, ILA BERLIN.2014.

[36] E.E., K. Solar-Thermochemical Hydrogen. 2010 [cited 201722 August]; Available from: http://www.me.udel.edu/research_groups/prasad/research/solartherm.html.

[37] Tingate, G.Some geometrical properties of packings of equal spheres in cylindrical vessels. Nuclear Engineering and design, 1973; 24(2), 153-179.

[38] Burtseva, L., et al. Modeling of Monosized Sphere Packings into Cylinders: Univ., Fak. für Mathematik.;2015.

[39] Van Antwerpen, W., C. Du Toit, and P. Rousseau. A review of correlations to model the packing structure and effective thermal conductivity in packed beds of mono-sized spherical particles. Nuclear Engineering and design, 2010; 240(7), 1803-1818.

[40] Fumizawa, M., Y. Kaneko, and M. Izumi. Porosity Effect in the Core Thermal Hydraulics for Ultra High Temperature Gas-Cooled Reactor. Journal of Systemics, Cybernetics and Informatics, 2008; 6(6), 86-92.

[41] Oktajianto, H., E. Setiawati, and V. Richardina. Modelling of HTR (High Temperature Reactor) Pebble-Bed $10 \mathrm{MW}$ to Determine Criticality as A Variations of Enrichment and Radius of the Fuel (Kernel) With the Monte Carlo Code MCNP4C. International Journal of Science and Engineering, 2015; 8(1), 42-46.

[42] Cervone, A., et al. Development of hydrogen peroxide monopropellant rockets. AIAA paper, 5239, 2006.

[43] Tuinier, M., et al. Cryogenic $\mathrm{CO} 2$ capture using dynamically operated packed beds. Chemical Engineering Science, 2010; 65(1), 114-119.

[44] Ali, A.H., S. Ganguly, and A.B.M. Shariff. Simulation of cryogenic packed bed using 1-dimensional pseudo homogeneous model. J. Appl. Sci.,2014; 14, 3118-3121. 
Journal of Thermal Engineering, Research Article, Vol. 6, No. 2, Special Issue 11, pp. 152-169, March,2020

[45] Wieckert, C., et al. Syngas production by thermochemical gasification of carbonaceous waste materials in a $150 \mathrm{kWth}$ packed-bed solar reactor. Energy \& fuels, 2013; 27(8), 4770-4776.

[46] Reich, L., et al. Heat and mass transfer model of a packed-bed reactor for solar thermochemical CO2 capture. in Proc. of 15th Int. Heat Trans. Conf. 2014.

[47] Piatkowski, N., C. Wieckert, and A. Steinfeld. Experimental investigation of a packed-bed solar reactor for the steam-gasification of carbonaceous feedstocks. Fuel processing technology, 2009; 90(3), 360-366.

[48] Bellouard, Q., et al.A high temperature drop-tube and packed-bed solar reactor for continuous biomass gasification. in AIP Conference Proceedings, AIP Publishing.2017.

[49] Wieckert, C. Solar Carbothermic Production of Zinc, SFERA Winter School Solar Fuels \& Materials, 2011; 32.

[50] Pvt.Ltd, D.I. Inert Ceramic Balls [cited 2016 07/09]; Available from: http://devsongroup.com/site/index.php?pid=0009.0001.

[51] Lopez-Hernandez, H.D. Experimental analysis and macroscopic and pore-level flow simulations to compare non-Darcy flow models in porous media. 2007.

[52] Getachew, D., W. Minkowycz, and J. Lage. A modified form of the $\kappa-\varepsilon$ model for turbulent flows of an incompressible fluid in porous media. International Journal of Heat and Mass Transfer, 2000; 43(16), 2909-2915.

[53] Pedras, M.H. and M.J. de Lemos. Computation of Turbulent Flow in Porous Media Using a Low-Reynolds K- $\varepsilon$ Modeland AN Infinite Array of Transversally Displaced Elliptic Rods. Numerical Heat Transfer: Part A: Applications, 2003; 43(6), 585-602.

[54] E, F., MACROSCOPIC MODELING OF TURBULENCE IN POROUS MEDIA

[55] Xu, C., Z. Song, and Y. Zhen. Numerical investigation on porous media heat transfer in a solar tower receiver. Renewable Energy,2011; 36(3), 1138-1144.

[56] Alazmi, B. and K. Vafai. Analysis of variants within the porous media transport models. Journal of Heat Transfer, 2000; 122(2), 303-326.

[57] Villafán-Vidales, H., et al. Heat transfer simulation in a thermochemical solar reactor based on a volumetric porous receiver. Applied Thermal Engineering,2011; 31(16), 3377-3386.

[58] Vafai, K.a.A., A. Non-Darcian Effects in a confined Forced convective Flows,. Chemical Engineering Sciences, 1998; 2523-2532.

[59] Hwang, G.J.C.C.H. Heat Transfer Measurment and Analysis for Sintred Porous Channels ASME Journal Of Heat Transfer,1994; 456-464

[60] Dixon, A.G.C., D. L. Theoretical Prediction of effective Heat Transfer Parameters in Pached Bed AIChE Journal,1979; 663-676.

[61] Abenbach, E. Heat and flow charactaristics of packed beds. Experimental Thermal and fluid Science, 1995; 17-27.

[62] Vafai, K. and A. Amiri. Non-Darcian effects in confined forced convective flows. Transport phenomena in porous media, 1998; 1, 313-329.

[63] K, K., Modeling of composite heat transfer in open-cellular porous materials at hight temperatures

[64] Nelson, A.T., et al. Thermal expansion, heat capacity, and thermal conductivity of Nickel Ferrite (NiFe2O4). Journal of the American Ceramic Society, 2014; 97(5), 1559-1565.

[65] Massot, M., et al. Critical behavior of $\mathrm{CoO}$ and $\mathrm{NiO}$ from specific heat, thermal conductivity, and thermal diffusivity measurements. Physical Review B, 2008; 77(13), 134438.

[66] Schrettle, F., et al. Wüstite: electric, thermodynamic and optical properties of FeO. The European Physical Journal B-Condensed Matter and Complex Systems,2012; 85(5): p. 1-12.

[67] Lewis, F. and N. Saunders. The thermal conductivity of $\mathrm{NiO}$ and $\mathrm{CoO}$ at the Neel temperature. Journal of Physics C: Solid State Physics, 1973; 6(15), 2525.

[68] Wu, Z., et al. Coupled radiation and flow modeling in ceramic foam volumetric solar air receivers. Solar Energy,2011; 85(9),2374-2385. 